Metz, France; ${ }^{4}$ Sorbonne Université, INSERM, AP-HP, Hôpital Saint-Antoine, Department of Rheumatology, Paris, France; ${ }^{5}$ nserm, CHRU Nancy, Université de Lorraine, CIC-1433 Epidémiologie Clinique, Nancy, France $;{ }^{6} \mathrm{CHU}$ Caen, Department of Rheumatology, Caen, France

Background: Many trials investigated the beneficial effect of physical activity (PA) on physical function (PF) in people with osteoarthritis (OA), but factors involved in this relationship are poorly understood. Considering the link between $\mathrm{OA}$ and obesity and obesity-related disorders, body composition (BC) could be one of these factors.

Objectives: To examine the relationships between baseline components of PA and 5-year PF scores, considering BC variables measured at 3 years as potential mediators in theses associations (Figure).

Methods: We used data from the KHOALA cohort, a French population-based multicenter cohort of 878 patients with symptomatic knee and/or hip OA, aged between 40 and 75 years old. Baseline PA intensity (Metabolic Equivalent of Task, MET), frequency (times/week), duration (hours/week) and type (weight-bearing or not) were assessed by the Modifiable Activity Questionnaire. PF was measured with the WOMAC questionnaire at 5 years (higher scores = greater functional limitations).

Skeletal muscle mass (grams) and fat mass (grams) were measured by dual X-ray absorptiometry (DXA) in 358 patients at 3 years. Fat mass index $\left(\mathrm{kg} / \mathrm{m}^{2}\right)$, appendicular fat mass $(\mathrm{kg}), \%$ of fat mass, lean mass index $\left(\mathrm{kg} / \mathrm{m}^{2}\right)$, appendicular muscle mass $(\mathrm{kg})$, skeletal muscle mass index $\left(\mathrm{kg} / \mathrm{m}^{2}\right.$ or \%) were calculated based on DXA data. Sarcopenia was defined according to the FNIH Sarcopenia Project recommendations.

A causal mediation analysis was used to highlight the mediating role of $B C$ variables. Bivariate analyses (multiple linear and logistic regressions) were performed to select the variables of interest. Separate generalized linear models were used to describe the relationships between PA components, PF and selected BC variables. Unadjusted and adjusted for baseline confounders (age, gender, number of comorbidities, disease duration, mental health and vitality scores) models were ran.

Results: A 1-MET increase in baseline PA intensity was significantly associated with an improvement in PF at 5 years (-3 points). Weight-bearing PA was also significantly associated with better PF scores (-5 points).

A 1-MET-increase in PA intensity at baseline was associated with a subsequent decrease at 3 years in fat mass index $\left(-0.86 \mathrm{k} / \mathrm{m}^{2}\right)$, an increase in skeletal muscle mass index $(\geq 6 \%)$, and a decrease in $\%$ of fat mass $(-2 \%)$. Non-weight-bearing PA was significantly associated with a decrease in fat mass index $\left(-2.5 \mathrm{~kg} / \mathrm{m}^{2}\right)$. A 1-point increase in PF score was associated with a reduction in skeletal muscle mass index (calculated from body mass index, $-0.3 \%$ ) and an increase in skeletal muscle mass index (calculated from height, $+3 \mathrm{~kg} / \mathrm{m}^{2}$ ). The presence of sarcopenia was significantly associated with a degradation of $\mathrm{PF}(+7$ points).

Crude analyses indicated that $20.4 \%$ of the effect of baseline PA intensity on PF scores at 5 years was mediated by skeletal muscle mass index (calculated from height), $23.2 \%$ by fat mass index and $26.6 \%$ by $\%$ of fat mass. Similarly, $19.3 \%$ of the effect of baseline PA type on PF scores at 5 years was mediated by fat mass index and $15.1 \%$ by \% of fat mass. After adjustment, we found no longer evidence of a mediating role of $\mathrm{BC}$ variables in these associations.

Conclusion: We found significant associations between a 1-MET increase in PA intensity, weight-bearing PA at baseline and improvement in PF at 5 years, without any mediating role of $\mathrm{BC}$ variables. Further studies are needed to better understand the factors involved in these associations, especially psychosocial variables.

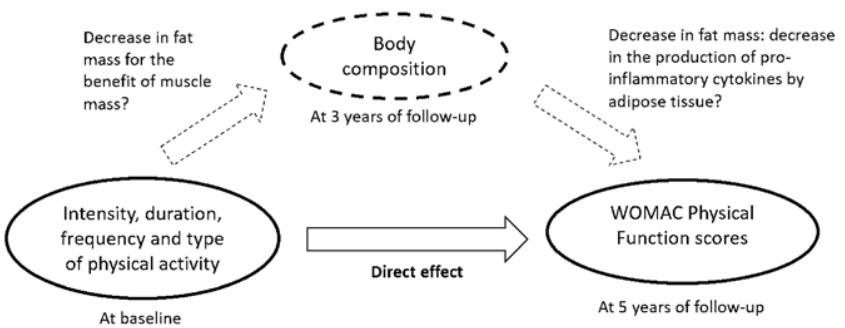

Disclosure of Interests: Maud Wieczorek: None declared, Christine Rotonda: None declared, Jérémie SELLAM: None declared, Francis Guillemin Grant/ research support from: Francis Guillemin received a grant from Expanscience paid to his institution., Anne-Christine Rat: None declared DOI: 10.1136/annrheumdis-2020-eular.2879

\section{FRI0385 MUSCLE FUNCTION AND QUALITY BUT NOT MASS PROTECT AGAINST MORE SEVERE KNEE PAIN TRAJECTORIES}

F. Pan ${ }^{1}$, J. Tian ${ }^{1}$, F. Cicuttini ${ }^{2}$, G. Jones ${ }^{1} .{ }^{1}$ University of Tasmania, Menzies Institute for Medical Research, Hobart, Australia; ${ }^{2}$ Monash University Medical School, Melbourne, Australia

Background: Evidence suggests that periarticular muscles have a role in the pathogenesis of pain, but results have not been consistent. We recently reported that pain population is heterogenous and consists of different subgroups of which the causes and mechanisms differ.

Objectives: To examine the association of muscle mass, leg strength, knee extensor strength, low-limb muscle quality with knee pain trajectories.

Methods: Data on 975 participants from a population-based older adult cohor study were utilised. Dual-energy X-ray absorptiometry was used to assess muscle/fat mass. Leg strength in both legs and dominant knee extensor strength were measured. Low-limb muscle quality was calculated (i.e. leg strength divided by lower-limb muscle mass). The Western Ontario and McMaster Universities Osteoarthritis Index pain questionnaire was used to measure knee pain at each time-point. Radiographic knee osteoarthritis (ROA) was assessed by X-ray. Group-based trajectory modelling was applied to identify pain trajectories. Multi-nominal logistic regression was used for the analyses.

Results: A total of 975 participants [Mean \pm SD: age $62.2 \pm 7.4$ years, body mass index (BMI) $27.8 \pm 4.6 \mathrm{~kg} / \mathrm{m}^{2}$ and $51 \%$ of females] were included in the analysis. Three distinct pain trajectories were identified: 'Minimal pain' (53\%), 'Mild pain' $(34 \%)$ and 'Moderate pain' (13\%). In multivariable analysis, both greater total and low-limb muscle mass were associated with an increased risk of 'Mild pain' [total muscle mass: relative risk (RR): 1.51 per SD increase, $95 \% \mathrm{Cl}$ : 1.14-1.98; low-limb muscle mass RR: 1.33 per SD increase, 95\% $\mathrm{Cl}: 1.07-1.66]$ and 'Moderate pain' [total muscle mass: RR: 2.57 per SD increase, $95 \% \mathrm{Cl}$ : $1.70-3.89$ ); low-limb muscle mass RR: 2.03 per SD increase, $95 \% \mathrm{Cl}$ : 1.47-3.80)] compared to the 'Minimal pain' trajectory group. After further adjustment for fat mass, these associations disappeared. Total muscle mass percentage was associated with a reduced risk of being worse pain trajectories. In relative to the 'Minimal pain' trajectory group, leg strength knee extensor strength and quality were associated with a reduced risk of being in more severe pain trajectories after adjustment for covariates $(R R=0.56$ to 0.71 per $S D$ increase, all $P<0.05)$. Similar results were observed in those with $R O A$

Conclusion: Muscle percentage, strength and quality, but not muscle mass itself are associated with a reduced risk of being more severe pain trajectories, suggesting that improving muscle composition, muscle function and power are of more clinically relevance to preventing the development and maintenance of worse pain trajectories.

Disclosure of Interests: None declared

DOI: 10.1136/annrheumdis-2020-eular.5461

\section{FRI0386 EARLY OSTEOARTHRITIS: IS ASYMPTOMATIC CLINICAL COURSE REAL?}

N. Martusevich ${ }^{1}$, S. Duben ${ }^{2}$, A. Aleshkevich ${ }^{1}$, A. Dmitrieva ${ }^{3}$, T. Bondar $^{4}$, K. Gudkevich ${ }^{3} .{ }^{1}$ Belarusian State Medical University, Minsk, Belarus; ${ }^{2}$ Minsk City Clinical Policlinic No.23, Minsk, Belarus; ${ }^{3}$ Minsk City Clinical Hospital No. 6, Minsk, Belarus; ${ }^{4}$ Minsk Regional Clinical Hospital, Minsk, Belarus

Background: Osteoarthritis $(\mathrm{OA})$ is the leading cause of disability among all RMDs. Early diagnosis of OA is complicated. So, there is an absence of clear markers of the diagnosis of $\mathrm{OA}$, and this issue is now being discussed.

Objectives: The aim of this study is to examine relatively healthy individuals without symptoms in order to evaluate MR-markers of early OA of the knee.

Methods: We included 29 relatively healthy individuals. 55,17\% $(n=16)$ were women. Median age was 35 (32-41) years. They didn't have any complaints, according to the preliminary criteria of early OA, symptoms of OA (1), didn't have any significant concomitant diseases and elevated ESR, CRP. The exclusion criteria were previous trauma, orthopedic surgery, X-Ray signs of OA. MRI was performed on 1,5 TI Siemens Magnetom Essenza. WORMS-scale was used to evaluate the knee joint structures.

Results: In all examined joints we observed small changes characteristic of symptomatic OA (osteophytes, cartilage damage etc.). In 4 knees we found undamaged cartilage ( 0 points). In 5 knees we observed cartilage damage $>=4$ points with marrow abnormality. In the Table 1 we present the frequency of any abnomaly ( $>=1$ points) in each parameter present in examined joints. The mos commonly asymptomatic changes were observed in the patellofemoral joint. Small osteophytes were the most common changes. 
Table 1. Number of examined knee joints with different anomalies according to WORMS (>=1 point).

\begin{tabular}{lccccc}
\hline Parameter & $\begin{array}{c}\text { MFTJ } \\
\text { (percent, total) }\end{array}$ & $\begin{array}{c}\text { LFTJ, } \\
\text { (percent, total) }\end{array}$ & $\begin{array}{c}\text { PFJ } \\
\text { (percent, total) }\end{array}$ & $\begin{array}{c}\text { S-region, } \\
\text { (percent, total) }\end{array}$ & $\begin{array}{c}\text { Total, } \\
\text { (percent, total) }\end{array}$ \\
\hline $\begin{array}{l}\text { Cartilage } \\
\text { Marrow }\end{array}$ & $19,44 \%(n=7)$ & $19,44 \%(n=7)$ & $75,00 \%(n=27)$ & - & $83,33 \%(n=30)$ \\
$\quad$ abnormality & $0,00 \%$ & $2,78 \%(n=1)$ & $0,00 \%$ & $13,89 \%(n=5)$ & $16,67 \%(n=6)$ \\
Bone cysts & $0,00 \%$ & $0,00 \%$ & $0,00 \%$ & $0,00 \%$ & $0,00 \%$ \\
Bone attrition & $66,67 \%(n=24)$ & $0,00 \%$ & - & - & $66,67 \%(n=24)$ \\
Osteophytes & $88,89 \%(n=32)$ & $86,11 \%(n=31)$ & $97,22 \%(n=35)$ & - & $100,00 \%(n=36)$ \\
Menisci & $0,00 \%$ & $2,78 \%(n=1)$ & - & - & $2,78 \%(n=1)$ \\
Ligaments & - & - & - & - & $0,00 \%$ \\
Synovitis & - & - & - & - & $33,33 \%(n=12)$ \\
Total & - & - & - & - & $100,00 \%(n=36)$ \\
& & & - & &
\end{tabular}

Besides, we calculated mean points in each parameter in the scale and compared it with the maximum score in this parameter (in percent). Table 2 shows the results. The most severe change was bone attrition.

Table 2. Mean points of different WORMS parameters in examined knee joints.

\begin{tabular}{lccccc}
\hline Parameter & $\begin{array}{c}\text { MFTJ } \\
\text { (percent, total) }\end{array}$ & $\begin{array}{c}\text { LFTJ, } \\
\text { (percent, total) }\end{array}$ & $\begin{array}{c}\text { PFJ } \\
\text { (percent, total) }\end{array}$ & $\begin{array}{c}\text { S-region, } \\
\text { (percent, total) }\end{array}$ & $\begin{array}{c}\text { Total, } \\
\text { (percent, total) }\end{array}$ \\
\hline Cartilage & $1,30 \%$ & $1,02 \%$ & $7,64 \%$ & - & $2,91 \%$ \\
Marrow & $0,00 \%$ & $0,37 \%$ & $0,00 \%$ & $4,63 \%$ & $0,31 \%$ \\
$\quad$ abnormality & & & & & \\
Bone cysts & $0,00 \%$ & $0,00 \%$ & $0,00 \%$ & $0,00 \%$ & $0,00 \%$ \\
Bone attrition & $15,37 \%$ & $0,00 \%$ & $0,00 \%$ & - & $1,75 \%$ \\
Osteophytes & $6,59 \%$ & $5,48 \%$ & $8,33 \%$ & - & $6,69 \%$ \\
Menisci & $0,00 \%$ & $0,93 \%$ & - & - & $0,46 \%$ \\
Ligaments & - & - & - & - & $0,00 \%$ \\
Synovitis & - & - & - & - & $12,04 \%$ \\
Total & - & - & - & - & $3,61 \%$ \\
\hline
\end{tabular}

We didn't observe asymptomatic lesions in the medial meniscus, marrow abnormality in MFTJ and LFTJ, subchondral cysts in any location, ligament lesions. Despite minimal osteophytes almost in all individuals, they didn't have any clinical features of knee OA.

Conclusion: MRI of the knee joints in the cohort of young relatively healthy individuals without clinical features of $O A$ revealed irreversible structural changes characteristic of symptomatic OA. There is no association between symptoms and structural damage. Based on these, we can make an assumption about asymptomatic stage of $\mathrm{OA}$. In order to distinguish between definitions of early asymptomatic OA as a disease onset and asymptomatic structural changes as reflection of metabolic disorders it is necessary to follow up and to perform an in-depth examination of these individuals.

References:

[1] Migliore, A., Scirè, C.A., Carmona, L. et al. The challenge of the definition of early symptomatic knee osteoarthritis: a proposal of criteria and red flags from an international initiative promoted by the Italian Society for Rheumatology. Rheumatol Int 37, 1227-1236 (2017).

Disclosure of Interests: Natalia Martusevich Shareholder of: k, Svetlana Duben: None declared, Alexander Aleshkevich: None declared, Alena Dmitrieva: None declared, Tatsiana Bondar: None declared, Katsiarina Gudkevich: None declared DOI: 10.1136/annrheumdis-2020-eular.6604

\section{FRI0387 A PROGNOSTIC MODEL OF PRE-RADIOGRAPHIC KNEE OSTEOARTHRITIS: DATA FROM THE OSTEOARTHRITIS INITIATIVE}

M. Camacho Encina ${ }^{1}$, V. Balboa-Barreiro ${ }^{1}$, I. Rego-Perez ${ }^{1}$, R. Paz González $^{1}$, V. Calamia ${ }^{1}$, L. Lourido ${ }^{1}$, C. Ruiz-Romero ${ }^{1}$, F. J. Blanco ${ }^{1} .{ }^{1} I N I B I C$, Rheumatology Research Group, A Coruña, Spain

Background: The improvement of the existing diagnostic methods to detect pre-radiographic knee $\mathrm{OA}(\mathrm{KOA})$ may facilitate the development of preventive strategies. It has been postulated that combining biochemical with clinical markers, may increase the prognostic power to detect who is at high risk for developing KOA.

Objectives: To validate and qualify the ability of 6 proteins with biomarker potential to generate a prognostic model of knee OA prediction through the combination of validated $O A$ biomarkers and clinical markers.

Methods: In the validation phase (Figure 1), 749 sera at the baseline visit belonging to participants from the Osteoarthritis Initiative (OAI) Cohort were randomly selected to blindly quantify 6 biomarkers using in-house custom sandwich microarrays built using the XMAP technology. Among these, only 540 participants have a Kellgren and Lawrence $(\mathrm{KL})$ grade $=0-1$ at the beginning of the OAI study in at least one knee. After a follow-up period of 96 months, 209 participants developed $\mathrm{KOA}$ in at least one knee $(\mathrm{KL} \geq 2)$ and were classified as incident group, whereas 331 did not developed the disease $(K L=0-1)$ and were classified as not-incident group. Statistical differences between the outcome groups were assessed by non-parametric Mann-Whitney $U$ tests. In the qualification phase $(n=540)$, univariate regression analyses were carried out to investigate whether the individual biomarkers were associated with the risk of KOA development. A clinical prognostic model was defined by stepwise regression analysis using clinical non-radiographic variables significantly associated with the OA incidence. The utility of the potential biomarkers, alone or in combination, was evaluated by comparing the Area Under the Curve (AUC) of the clinical prognostic model with the biomarkers plus clinical prognostic models. In addition, sen

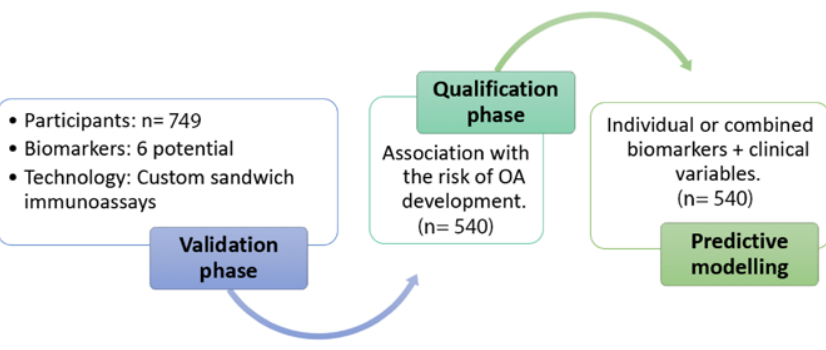

Figure 1. Study desing

Results: The incident group showed significant higher serum concentrations at the baseline visit $(p<0.05)$ for all the potential biomarkers analyzed in this study. Moreover, 5 of them were also significantly associated with the future appear ance of radiographic KOA, yielding Odds Ratios $(\mathrm{OR}) \geq 10 \mathrm{per} 10 \mu \mathrm{g} / \mathrm{ml}$ increase. Among all the possible combinations, the inclusion of 2 biomarkers to the clinical prognostic model showed a significant improvement of the predictive capacity (AUCs $=0.78$ vs $0.82, p=0,044)$ with $65 \%(95 \%$ Confidence Interval $(95 \% \mathrm{Cl})$ : $60-70 \%)$ specificity and $88 \%(95 \% \mathrm{Cl}: 81-91 \%)$ sensitivity. Variables included in the regression model and all metrics comparing the biomarkers plus clinical prognostic model with the clinical prognostic model are shown in Figure 2A. The ROC curves of the biomarkers-only model, clinical prognostic model and biomarkers plus clinical prognostic model are represented in Figure 2B.
$\mathbf{A}$

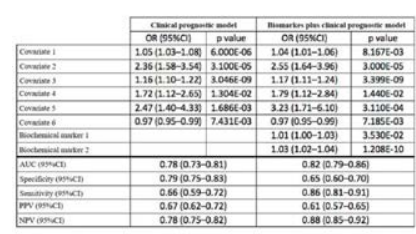

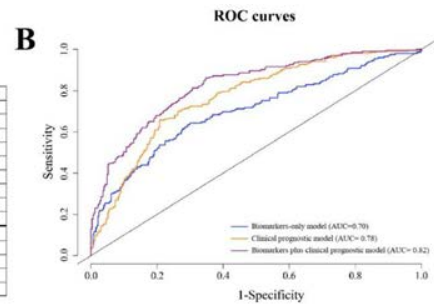

B
Figure 2. (A) Multivariate regression analysis (B) ROC curves of the models

Conclusion: We have generated a prognostic model for the prediction of KOA by combining biomarkers and clinical variables, which showed a putative utility in the clinical setting by improving the predictive capacity of a clinical prognostic model to identify patients at a higher risk to develop radiographic KOA.

Disclosure of Interests: Maria Camacho Encina: None declared, Vanesa Balboa-Barreiro: None declared, Ignacio Rego-Perez: None declared, Rocío Paz González: None declared, Valentina Calamia: None declared, Lucía Lourido: None declared, Cristina Ruiz-Romero: None declared, Francisco J. Blanco Grant/research support from: Sanofi-Aventis, Lilly, Bristol MS, Amgen, Pfizer, Abbvie, TRB Chemedica International, Glaxo SmithKline, Archigen Biotech Limited, Novartis, Nichi-iko pharmaceutical Co, Genentech, Jannsen Research \& Development, UCB Biopharma, Centrexion Theurapeutics, Celgene, Roche Regeneron Pharmaceuticals Inc, Biohope, Corbus Pharmaceutical, Tedec Meij Pharma, Kiniksa Pharmaceuticals, Ltd, Gilead Sciences Inc, Consultant of: Lilly, Bristol MS, Pfizer

DOI: 10.1136/annrheumdis-2020-eular.4450

\begin{tabular}{|l|l|}
\hline FRI0388 & ARE WE OVERLOOKING OSTEOARTHRITIS? \\
& - A COMPARATIVE STUDY OF PAIN, FUNCTION \\
& AND QUALIFY OF LIFE IN PATIENTS WITH HAND \\
& OSTEOARTHRITIS AND RHEUMATOID ARTHRITIS
\end{tabular}

D. Almeida ${ }^{1,2}$, E. Costa ${ }^{1}$, F. Guimarães ${ }^{2}$, S. Azevedo ${ }^{2}$, J. Rodrigues $^{2}$, J. Silva $^{2}$, D. Faria ${ }^{2}$, F. Teixeira ${ }^{2}$, C. Afonso ${ }^{2}$, J. Tavares-Costa ${ }^{2}$, J. Neves ${ }^{1}$, A. R. Ribeiro ${ }^{1}$, 